\title{
PESQUISANDO O TEATRO PARA BEBÊS: DESAFIOS À EDUCAÇÃO E ÀS ARTES NA PRIMEIRÍSSIMA INFÂNCIA
}

\author{
Patrícia Dias Prado ${ }^{1}$ \\ Adriele Nunes da Silva ${ }^{2}$
}

\begin{abstract}
Resumo:
Este artigo apresenta análises de pesquisa sobre o Teatro para bebês e suas relações com a educação na infância, concebendo-o como possibilidade de reconstrução do convívio na diferença, de educação estética e de formação humana, desde o nascimento. No desafio metodológico de construção de pesquisas com bebês e artistas, junto aos estudos sociais da infância, na interface com as artes, realizou-se pesquisa de campo com observação de mais de sessenta espetáculos infantis nacionais e estrangeiros, seus elementos cênicos, a atuação dos/as artistas e suas relações com a plateia, em especial, com as crianças e adultos/as, com registro em diário de campo e com seleção de quatro espetáculos brasileiros para bebês, para aprofundamento das observações e entrevistas semiestruturadas com os/as artistas. As análises abrem uma problemática central à constituição e legitimação dos/as bebês como espectadores/as emancipados/as, revelando novas concepções de infância que desafiam a educação e as artes na primeiríssima infância.
\end{abstract}

Palavras-chave: Teatro para bebês. Educação e Artes. Primeiríssima infância. Pesquisa.

\section{RESEARCHING THE THEATER FOR BABIES: CHALLENGES TO EDUCATION AND ARTS IN THE EARLIEST CHILDHOOD}

\begin{abstract}
:
This paper presents an analysis of research on the Theater for babies and its relations with childhood education, conceiving it as a possibility of reconstruction of coexistence in difference, of aesthetic education and human formation, since birth. In the methodological challenge of building research with babies and artists, together with the social studies of childhood, in the interface with the arts, a field research was conducted with the observation of more than sixty national and foreign children's shows, their scenic elements, the artists' performance and their relations with the audience, especially with children and adults, with record in field diary and with the selection of four Brazilian shows for babies, to deepen the observations and semi-structured interviews with the artists. The analyses open a central problematic to the constitution and legitimation of babies as emancipated spectators, revealing new conceptions of childhood that challenge education and the arts in very early childhood.
\end{abstract}

Keywords: Theater for babies. Education and Arts. Earliest childhood. Research.

\footnotetext{
${ }^{1}$ Profa. Dra. da Faculdade de Educação, da Universidade de São Paulo, FEUSP, na área da Infância. Mestra e Doutora em Educação, FE-UNICAMP. Pós-doutora em Artes Cênicas, ECA-USP. Coordenadora do Grupo de Pesquisa (CNPq) Pesquisa e Primeira Infância: linguagens e culturas infantis (FEUSP). E-mail: patprado@usp.br. ${ }^{2}$ Pedagoga e Mestra em Educação pela FE-USP, finalizando a licenciatura em Arte-Teatro pelo Instituto de Artes, UNESP/SP. Professora do Ensino Superior privado, de Educação Infantil e de Ensino Fundamental em redes públicas paulistas. Membro do Grupo de Pesquisa (CNPq) Pesquisa e Primeira Infância: linguagens e culturas infantis (FEUSP). E-mail: drilor@hotmail.com.
} 


\section{Introdução}

Ainda que pesquisas recentes apontem para a importância e relevância da relação entre as artes e a educação da primeiríssima infância, sobretudo, como aferem documentos como os Referenciais Curriculares Nacionais para a Educação Infantil (RCNEI) (BRASIL, 1998), esse diálogo nem sempre está presente nas concepções e práticas das instituições de educação da infância, que buscam caminhos para romper com a escolarização precoce de bebês e crianças pequenas (SAYÃO, 2008; SOUZA, 2010, 2016; PRADO; SOUZA, 2017).

Nesse cenário capitalista de antecipação da alfabetização, de negação dos corpos, de priorização do racional e do produtivo, busca-se aqui uma pedagogia da presença que contemple a primeiríssima infância, suas especificidades e direito à comunicação não verbal, com propostas educativas fundamentadas nas artes, pautada nos movimentos, gestualidades e expressividades de corpos inteiros (PRADO, 2015) e nas experiências artísticas (FARIA; RICHTER, 2009). No encontro entre arte e infância revelam-se lacunas em relação à construção de epistemologias e metodologias de pesquisa com bebês e artistas e em relação à formação de profissionais da infância: professores/as, pesquisadores/as e artistas.

Para tanto, este artigo pretende trazer análises de pesquisa qualitativa em educação (LÜDKE; ANDRÉ, 1986), sobre o Teatro para bebês e suas relações com a educação na infância, concebendo-o como possibilidade de reconstrução do convívio na diferença, de educação estética e de formação humana, desde o nascimento (SILVA, 2017), aprofundando questões e problemáticas analisadas inicialmente em Silva (2012), fomentando novos debates e enfrentando a escassez acadêmica que envolve esta temática

$\mathrm{Na}$ busca por entender o que seria o Teatro para bebês, quais suas possíveis interlocuções com as recentes concepções de infância e o que poderia esse teatro na cena contemporânea, assistiu-se a mais de sessenta peças teatrais destinadas a crianças de variadas idades, entre 2010 e 2016, na capital e no interior de São Paulo, em outras capitais como Rio de Janeiro, Porto Alegre e Fortaleza, além de outras cidades estrangeiras, como Évora, Lisboa/PT, Bologna/IT, Budapeste/HU, Varsóvia/PL e Berlim/DE³.

No Brasil, um primeiro contato investigativo com peças para bebês foi por meio da participação em festivais e eventos como Conversas poéticas entre Arte e bebês ${ }^{4}$, no Centro Cultural São Paulo (CCSP/SP), organizado pela Cia. Zin, quando a pesquisa teve um salto, estendendo seu alcance das observações dos/as bebês para problematizações que envolviam os contextos de produção, os processos de criação e de encenação das peças junto aos/às artistas.

No estabelecimento de contatos mais próximos com as companhias e artistas foram selecionadas quatro companhias e seus espetáculos: $O$ que sonhei?, da Cia. Zin, de São Paulo/SP ${ }^{5}$, Berço de Espuma, do Grupo Papo Corpóreo, de Londrina/PR ${ }^{6}$, A Bailarina, do Grupo Sobrevento, de São Paulo/SP ${ }^{7}$ e Cuco - a linguagem dos bebês no Teatro, da Cia. Caixa

\footnotetext{
${ }^{3}$ Por meio do Programa de Intercâmbio-Mérito Acadêmico, da Universidade de São Paulo (USP).

${ }^{4}$ Em 2011, com palestras, conversas abertas ao público, mesas redondas, vivências e o Workshop Baby-Art para educadores, com Anna Marie Holm (2007). Apresentação do evento disponível em: https://vimeo.com/39665898. Acesso em: 16 abr. 2021.

${ }^{5}$ Disponível em: https://ciazin.wordpress.com/. Acesso em: 30 jan. 2021.

${ }^{6}$ Disponível em: http://papocorporeo.blogspot.com/. Acesso em 30 mar. 2021.

${ }^{7}$ Disponível em: http://www.sobrevento.com.br/. Acesso em 30 mar. 2021.
} 
do Elefante, de Porto Alegre/RS ${ }^{8}$, também por meio de outros festivais brasileiros de Teatro para a primeiríssima infância.

Além de assistir e reassistir repetidamente a esses espetáculos em diversos momentos e plateias, com registro em caderno de campo, realizaram-se entrevistas semiestruturadas (com uso do gravador para registro dos depoimentos ${ }^{9}$ ), com base em um primeiro roteiro prévio, que depois foi ampliado num segundo roteiro, com base em novas reflexões e questionamentos, mediante autorização dos/as artistas, diretores/as e um pesquisador que auxiliava a Cia Caixa do Elefante nas pesquisas sobre infância e na elaboração das dramaturgias das peças.

As entrevistas tiveram como objetivo aprofundar as observações e investigar as concepções de infância dos/as envolvidos/as nas construções e apresentações de espetáculos com foco para o público infantil de zero a três anos, pensando na possibilidade de diálogos com os demais públicos, respeitando o Código de Ética da Universidade de São Paulo (USP) ${ }^{10}$. As questões abertas versaram sobre suas concepções de infância, de Teatro para bebês, de educação e artes na infância, sobre o processo de criação das peças, sobre as referências teóricas e práticas para as construções dramatúrgicas, o que eles/as têm aprendido com as crianças, especialmente com as bem pequenas e sobre estas como espectadoras ativas do Teatro para bebês.

A observação dos espetáculos centrou-se nas relações entre crianças e artistas, como também entre as crianças e delas com seus/suas responsáveis: o que faziam durante as apresentações, quais eram suas formas de observação, participação, expressão, comunicação (ou não), como oslas artistas lidavam com estas linguagens, antes, durante e ao final dos espetáculos, além da composição do cenário, enredo e da própria dramaturgia.

Essa forma de construir metodologias de pesquisa com bebês e artistas, observando-os em cena e em relação, entrevistando os/as artistas e refletindo sobre as artes na Educação da primeira infância tem inspirado uma produção recente de pesquisas que exibem em comum os desafios epistemológicos e metodológicos à educação e às artes na infância (COSTAS, 2016), tanto mais na primeira infância (PRADO, 2017; PRADO; SOUZA, 2017; PRADO; GOETTEMS, 2019; SILVA; PRADO, 2020).

Os materiais produzidos foram analisados de forma articulada e à luz da produção brasileira recente no campo do Teatro para infância e dos recentes estudos sociais da infância, como a Sociologia da Infância e a Pedagogia da Educação Infantil, na interface com as Artes, na produção brasileira e estrangeira sobre o Teatro para primeira infância, além da produção sobre o Teatro, propriamente dito, na construção de metodologias de pesquisa que elevem as vozes das crianças (FARIA; DEMARTINI; PRADO, 2009; MARTINS FILHO; PRADO, 2011), mesmo daquelas que ainda não falam e de seus/suas interlocutores/as.

Baseou-se nas análises, na concepção epistemológica de que as crianças são sujeitos históricos, competentes quanto à interpretação da realidade social na qual estão inseridas. Almejando contribuir com metodologias que propusessem um trabalho de parceria entre adultos/as e crianças, a observação das crianças, bem como de suas participações, protagonismos, agenciamentos (PROUT, 2005) e, sobretudo, transgressões - pilares fundamentais para o processo de construção das análises deste artigo.

\footnotetext{
${ }^{8}$ Disponível em: http://www.caixadoelefante.com.br/. Acesso em: 20 abr. 2021.

${ }^{9}$ Que foram transcritos e enviados aos/às artistas para nova autorização.

10 Disponível em: http://www.leginf.usp.br/?resolucao=resolucao-no-4871-de-22-de-outubro-de-2001. Acesso em: 25 abr. 2021.
} 
Ao focar nas atitudes transgressoras de bebês que "invadiram" o palco ou a cena, rompendo com os códigos teatrais adultos e propondo outras dinâmicas, pode-se questionar o Teatro para bebês e a nós adultos/as, no palco ou na plateia. Será que junto aos/às bebês se deixará de pensar em Teatro e se passará a pensar em Performances com bebês, ao invés de apresentações para eles/as? Afinal, que Teatro é este que passa a pensar nos/as bebês brasileiros/as na cena contemporânea? Que possibilidades estéticas, pós-dramáticas e performativas inauguram ao dialogar com as recentes concepções de infâncias e de artes (no caso, o Teatro) junto às crianças muito pequenas?

\section{O Teatro "para" bebês: uma arte menor?}

O Teatro para bebês, no hibridismo entre distintos campos artísticos, contribui para a formação de meninos e meninas para além das concepções desenvolvimentistas e centradas no indivíduo, favorecendo a formação humana, solidária, diversa, sensível e poética (FRABETTI, 2009). Para fazer obras que vão ao encontro da sensibilidade estética e poética das crianças pequeñas e bem pequenas faz-se necessário conhecê-las com um olhar não hierarquizado, nem infantilizado, muito menos adultocentrado.

Esse Teatro busca, sobretudo, não excluir quem antes era excluído, já que quando os/as bebês estão presentes, o Teatro é para eles/as. Eles/as estão incluídos/as, possibilitando seu contato com universos criativos e "(...) contribuindo com a formação artística e cultural de crianças cidadãs” (LENGOS, 2007, p.39), em diálogo com crianças de diferentes idades presentes nos espetáculos, questionando suas classificações etárias, pois “(...) fazer teatro para crianças pequenas implica uma intensa qualidade de participação humana e, certamente, tratase de uma tentativa de superar as barreiras de idade (...)" (FRABETTI; MANFERRARI, 2006, p.94 apud BARBOSA; FOCHI, 2011, p.35).

A partir da Segunda Modernidade ${ }^{11}$, tem-se um processo de reinstitucionalização da infância, culminando em uma análise morfológica, sintática e semântica das culturas da infância, centralizando-as no processo de compreensão das mudanças estruturais contemporâneas. Nesse momento histórico, mais especificamente, na década de 1980, surge o Teatro para bebês, uma "obra aberta" (ECO, 1991) que está se configurando em um Teatro pensado para todos/as, inclusive para os/as muito pequenos/as.

O Teatro para bebês surgiu em países europeus, como Itália, Espanha, Eslovênia, França, Bélgica $^{12}$ e, posteriormente, passou a ter repercussão em países como o Brasil. Se observarmos historicamente, trata-se de uma conquista social da primeiríssima infância (PEREIRA, 2014), contudo, por ser uma vertente recente ainda está imersa em muitas controvérsias, desconfianças no meio artístico, crítico e intelectual.

Todavia, a cena teatral contemporânea tem revelado encenações que surgem com força, evidenciando, por parte dos/as artistas, o crédito na capacidade poética, no protagonismo e no

\footnotetext{
${ }^{11}$ A Segunda Modernidade caracteriza-se pelo complexo conjunto de rupturas sociais, bem como da substituição de uma economia predominantemente industrial para uma economia de serviços, a ruptura do “(...) equilíbrio de terror entre os dois blocos (...) têm sérias implicações no estatuto social sobre a infância e nos modos, diversos e plurais das condições actuais de vida das crianças" (SARMENTO, 2003, p. 6s.).

${ }^{12}$ De acordo com dados do site Small Size, European Network for the Difusion and Development of Performing Arts for Early Childhood, criado pela Cia. teatral italiana La Baracca - Testoni Ragazzi, em 2005. Disponível em: https://www.testoniragazzi.it/doc.php?iddoc=419\&lang=en. Acesso em: 30 mar. 2021.
} 
agenciamento dos/as bebês, bem como na possibilidade dessa arte que emerge e busca, como aponta o ator Luiz André Cherubini (2009) ${ }^{13}$, que o teatro retorne à cena ritualística, ao sagrado, bem como à presença potente e viva do público.

Assim como no jogo, ou na brincadeira, as cenas do Teatro para bebês têm revelado apresentações com uma atmosfera intimista, diferindo-se do Teatro espetacular. Nesse sentido, o Teatro para bebês reinventa teatralidades (SARRAZAC, 2013), compondo a cena contemporânea, dispensando as cortinas, propondo outros diálogos para e com as crianças muito pequenas. Como escrevera Pavis (2011) sobre o Teatro anarquista de Artaud (2006), superando “(...) o Teatro burguês baseado no verbo, na repetição mecânica e na rentabilidade, reatando com a ordem imutável do rito e da cerimônia” (PAVIS, 2011, p. 346).

Ao longo das entrevistas realizadas com os/as artistas, percebeu-se o interesse comum de algumas companhias, além de longa trajetória anterior, com o Teatro de animação. Seria essa uma coincidência? Lançam-se algumas hipóteses relativas à proximidade do Teatro de animação e o Teatro para bebês no que tange à ritualística, ao sagrado e à atmosfera intimista. O Teatro de formas animadas aproxima-se, em linhas gerais, do que propõe Artaud (2006) um teatro que se centra no gesto, na respiração e nos corpos, renuncia à supremacia da palavra e à distância entre atores, atrizes e plateia, no qual todos/as estão envolvidos/as no processo e no ato teatral. Ao dialogar com o transcendental, prioriza uma comunicação que deixa de acontecer por meio da consciência racional, como nos rituais primitivos, com aspectos animistas e seus objetos sagrados.

Visualmente, carregado em simbologias, o Teatro de animação liga-se ao Teatro de máscaras, de bonecos, bem como à capacidade dos seres humanos de animar objetos. Para Amaral (1991), o Teatro de animação tem como característica ser pouco centrado no texto, dialogando com as crianças pequenas que dominam outras formas de comunicação para além da racional e embasada no verbo. Nesse sentido, o Teatro para bebês também dialoga com o Teatro pós-dramático ou pós-moderno (LEHMANN, 2007, 2013; MACHADO, 2011), já que os/as bebês não separam os conhecimentos racionais dos corporais (SAYÃO, 2008), vivenciando, juntamente aos/às artistas, as narrativas com seus corpos, movimentos, múltiplas linguagens, sendo performers e criadores/as de seu faz de conta (MACHADO, 2010).

Os quatro espetáculos selecionados, concebidos para apenas algumas pessoas, criavam propositadamente uma atmosfera de intimidade e uma relação de proximidade entre palco e público, reunindo relações, respirações, sentimentos, emoções e corpos. No final da peça $A$ Bailarina, por exemplo, um bebé foi ao palco numa atitude de pedir aplausos ao público ao lado da atriz, mostrando que estava de corpo inteiro e presente, como se fosse parte do espetáculo. Houve também uma senhora em lágrimas durante toda a peça, confirmando que se aproximar dos/as bebés não nos torna infantilizados/as, mas ainda mais humanos/as.

Em muitos outros momentos observados nos espetáculos, os/as bebês pareciam devanear junto às cenas e avançavam sobre os códigos teatrais, transgredindo o limite entre o palco e a plateia, rompendo com a ideia de Teatro como algo hermético, trazendo possibilidades de compreensão de mundo não lineares e uma estética pós-dramática, ligada à Performance (de fronteiras incertas entre teatro, dança, música, "contação" de história, poesia, desenho, instalação etc.) Estes modo de pensar, fazer e viver Arte têm se ligado ao modo de experimentar,

\footnotetext{
${ }^{13}$ Em entrevista realizada por Souza (2010), em 28/08/2009, cedida pela mesma e autorizada pelo entrevistado.
} 
de imaginar, de ser e de construir relações das crianças pequenas e bebês. Ao aproximar Arte teatral e vida em criação cênica, as produções artísticas investigadas revelam cenários em que as crianças são as coprodutoras desta Arte, que exclui estruturas rígidas da construção dramatúrgica.

Ao pretender dialogar com outros modos de ver o mundo, advindos daqueles/as que não constituem o pensamento hegemônico e que estiveram à margem, como as crianças, o Teatro para bebês escancara as epistemes sulistas, como proposto por Boaventura de Sousa Santos (s.d.), ao aproximar pessoas com interesses iguais e diferentes em uma reunião comum, reavendo ideais democráticos (GUÉNOUN, 2003), propondo fruição estética e compartilhamento social (PEIXOTO, 2015) ${ }^{14}$.

A presença cênica das atrizes e atores, seus gestos, movimentos e expressões são fundamentais no Teatro para bebês (CHERUBINI, 2013) ${ }^{15}$, assim como o processo de experimentação cênica de imagens arquetípicas do inconsciente coletivo, trazendo à tona temáticas sobre ancestralidade e humanidade, entre humanos/as que se reúnem frente ao caos estabelecido na vida contemporânea, contra os desencontros e desumanidades. Além de ser um Teatro a que todos/as podem ir, trata-se de um convite ao Teatro e à vida pública, de formação de público, de convívio entre pares e diferentes, entre pessoas de muita e de pouca idade ${ }^{16}$. Isso remete à sociedade pré-moderna, em que as crianças eram parte da vida pública, isto é, “(...) elas eram públicas, no sentido de estarem no espaço aberto" (QVORTRUP, 2014, p.27) e, atualmente, não apenas as crianças estão reclusas em lugares determinados, enclausuradas, como também os/as adultos.

O caráter do espaço público e a participação dos cidadãos e cidadãs (de pouca ou muita idade) na vida pública são alterados. $\mathrm{O}$ Teatro para bebês alerta sobre o alijamento do direito à cidade e ao seu pertencimento, bem como dos artefatos culturais, sociais, históricos, como museus, teatros e lugares que caracterizariam a cidade como um lugar de vivência coletiva, interativa e educativa. Segundo David Harvey (2013, p.33), o direito à cidade não seria apenas um direito condicional de acesso ao que já existe, mas sim “(...) um direito ativo de fazer a cidade diferente, de formá-la mais de acordo com nossas necessidades coletivas", definindo um modo alternativo de simplesmente ser humano/a em uma tentativa de re-imaginar e re-fazer os contextos urbanos.

Na busca por considerar a apropriação dos espaços pelas crianças pode-se vislumbrar suas impressões e marcas simbólicas e culturais nos Teatros para bebês, alterando o que neles é realizado, entendendo que as crianças, mesmo as muito pequenas como os/as bebês, não são

14 Em entrevista com Elenira Peixoto, diretora e artista da Cia. Zin. Disponível em: http://projetooqueeusonhei.blogspot.com.br/. Acesso em: 23 abr. 2021.

${ }^{15}$ Em entrevista realizada por Antonio Carlos Bernardes, 15/10/2013, na sede do Grupo Sobrevento, São Paulo/SP, para o projeto Novo Sítio CBTIJ Web - Atualização da Memória, Prêmio FATE 2012, Secretaria de Cultura do Rio de Janeiro. Disponível em: http://cbtij.org.br/eduardo-tolentino-2/. Acesso em: 25/04/2021.

\footnotetext{
${ }^{16}$ Não apenas os/as bebês, como crianças, jovens e adultos/as que nunca foram ao Teatro passam a ir para levar os/as bebês (como já acontecia com o Teatro Infantil). No relato de uma atriz da Cia. La Casa Incierta, ao pesquisador Luiz Pereira (2014), sobre a experiência de apresentar o Teatro para bebês para uma creche da Ceilândia, Brasília/DF: “(...) o Teatro para bebês é uma estratégia de levar, também, o público adulto que se não fosse 'pela mão da criança muito pequena', talvez não iria ao Teatro” (PEREIRA, 2014, p.117).
} 
apenas espectadores/as dos acontecimentos da vida, são protagonistas, produzem e reproduzem culturas (FERNANDES,1979; PRADO, 1999). Nesse sentido, até que ponto as apresentações cênicas estudadas são reveladoras dessas marcas, pertencimentos e agenciamento das crianças?

\section{O que propõem esses teatros?}

A gente vê o bebê desde agora, porque há infelizmente uma tendência de sempre projetar essa criança, então, no futuro ele virá a ser, então, é um bebê que já está ali, com potencialidades (...) estamos com essa criança presente e percebendo essa criança que pesquisa, esse bebê pesquisador, tudo para ele é objeto (...) a gente tem essa concepção de infância mesmo, de olhar a criança aqui, o bebê de igual para igual. Não de cima (Entrevista com o Grupo Papo Corpóreo, 21/08/2011).

Os espetáculos e companhias para a primeiríssima infância foram selecionadas por apresentarem relevante contraponto à maioria das produções teatrais infantis, no Brasil, que foram e ainda são carregadas de didatismos moralizantes, dramaturgias previsíveis e repetitivas dos contos tradicionais (CARNEIRO NETO, 2003, 2014), entrecruzadas por visões de mundo empobrecidas e maniqueístas que revelam “(...) uma produção cultural específica carregada de efeitos nitidamente perversos" (PUPO, 1999/2000, p. 337). Ora encontramos a ação dramática substituída pela fala, ora por movimentações, cenários, trajes e efeitos exagerados, deixando de lado a capacidade interpretativa do público.

Ainda assim, mesmo durante a década de 1950, podem-se destacar alguns diretores/as, autores/as, grupos e companhias que, dentro da categoria do Teatro infantil, podem ser considerados/as exceções, com experiências importantes até os dias de hoje. Em São Paulo, destaca-se o Teatro Escola São Paulo (TESP), com Julio Gouveia e Tatiana Belinky, de dramaturgias irreverentes e ideias pioneiras para a cidade de São Paulo, apresentando ao público escolar e demais espectadores/as, obras interessantes, "(...) apoiadas pelo poder público e com clara função artística e educativa" (PUPO, 2012, p.32), consideradas produções de vanguarda de um teatro elaborado esteticamente.

Outro destaque da cena do Teatro infantil no Brasil refere-se ao Tablado, no Rio de Janeiro, em 1951 (KOUDELA; ALMEIRA JÚNIOR, 2015), funcionando até os dias atuais. Em 1956, foi lançada a revista Caderno de Teatro ${ }^{17}$, com direção de Maria Clara Machado, cujo propósito consistia em divulgar os textos teatrais inéditos, de traduções a adaptações, assim como debater sobre o Teatro e seu contexto no Brasil da época. Na década de 1970, destaca-se o diretor, ator, artista plástico, figurinista e escritor argentino-brasileiro Ilo Krugli e seu espetáculo História de Lenços e Ventos, escrita e dirigida em 1974. Escreve Vieira (2008), que há no Brasil uma questão de considerar o Teatro infantil como arte menor, revelando um desconhecimento sobre o campo, já que não faltariam grandes autores/as e encenadores/as, como o próprio Ilo Krugli.

Para Fernandes (2000) e Vieira (2008) a obra História de Lenços e Ventos deu origem ao grupo Teatro Ventoforte, em São Paulo/SP, sendo este um marco da história do Teatro infantil brasileiro, apresentando uma qualidade poética nas obras encenadas para o público, pois passa a conceber "(...) a criança como protagonista, vista como um ser completo e pleno de todos seus direitos" (VIEIRA, 2008, p.13).

\footnotetext{
${ }^{17}$ Disponível em: http://otablado.com.br/cadernos-de-teatro/. Acesso em: 09 abr. 2021.
} 
O jogo e a possibilidade de invenção, imprevisto e as possibilidades de transformações passaram a ser o foco de tais textos dramatúrgicos e a ruptura da linearidade da trama questionada “(...) em benefício da ênfase da transformação simbólica (...), elemento fundador tanto do Teatro, como do jogo espontâneo da criança” (PUPO, 1991, p. 24). A imaginação e o jogo de fazer de conta passam a ser supervalorizados nos anos 1970, elementos do jogo infantil como base para o desenvolvimento da linguagem teatral.

Assim também propõe o recente Teatro para bebês, que tem revelado dramaturgias contemporâneas construídas com base nos movimentos, gestualidades e ações dos/as bebês, como coloca o diretor da Cia Caixa do Elefante, em entrevista ${ }^{18}$, sobre a peça Cuco - a linguagem dos bebês no teatro, e nas percepções dos/as artistas em relação aos/às pequenos/as, como diz a atriz Sandra Vargas, sobre A Bailarina, do Grupo Sobrevento: “(...) os bebês nos relembram de olhar para nosso entorno, nosso cotidiano, observando as pequenas situações cotidianas nós poderemos resgatar a poesia que há nessa situação e trabalhá-la em uma dramaturgia para eles" ${ }^{19}$, na busca por romper com os reducionismos e adultocentrismos, observados em dezenas de obras assistidas.

Leyva (2014) aponta para uma crise de identidade do Teatro infantil, vinculada à própria indefinição de sua episteme. Defende a ideia de existirem vários conceitos e identidades práticas que, por sua vez, dialogariam com as variadas infâncias, suas performances e com as diversas obras de Teatro infantil produzidas. Assim, a cena contemporânea traz desafíos sobre as definições teóricas que contemplam a heterogeneidade das práticas teatrais e em relação às diversas concepções de infầncia, arte, educação e sociedade.

Algumas propostas cênicas têm buscado observar esses câmbios históricos e conceituais em relação ao próprio teatro e ao constructo social infância, colocando em debate a discussão entre infância e dramaturgia (infantil), que "(...) vem passando por significativas mutações, podendo-se levar em cena textos de natureza variada, ou [ainda] nenhum texto (...)" (PUPO, 2012, p.17). Mudam-se as concepções de infância, modificando também a relação entre infância e Teatro, abarcando inclusive os/as bebês que eram excluídos/as desse contexto.

\section{Novas epistemologias das infâncias: bebês espectadores/as?}

Nas entrevistas realizadas com os/as artistas os/as bebês são considerados/as espectadores/as. Contudo, ao assistir às apresentações observou-se um cenário revelador de contradições. Por um lado, destacam-se avanços em relação às concepções de infância, por outro, revelam que as crianças estão além do que esperamos, para além dos nossos desejos, são outras e estão para além do que sabemos, queremos ou esperamos. Os/as bebês dissolvem a solidez do mundo e suspendem a certeza que se tem em uma “(...) absoluta descontinuidade, da possibilidade enigmática de que algo que não sabemos e que não nos pertence inauguram um novo início" (LARROSA, 2003, p.187).

Com isso, o Teatro para a primeiríssima infância tem buscado dialogar com algumas das descontinuidades em relação aos enigmas propostos pelas infâncias, como quando as

\footnotetext{
${ }^{18}$ Realizada em 01/08/2015, com Mario de Ballenti.

${ }^{19}$ Em entrevista para o Jornal Futura, no canal Futura. Disponível em: https://www.youtube.com/watch?v=JYE_Ij1PKE. Acesso em: 01 abr. 2021.
} 
crianças se surpreendem para além do esperado, espantando-se audivelmente e se expressando por meio de movimentações não esperadas, não se controlando (se é que deveriam) ou quando escapam das barreiras de contenção formada pelos/as adultos/as e invadem a cena, transgredindo e subvertendo os códigos teatrais por desconhecimento, desejo, ou ambos. O que revelam os/as bebês que invadem a cena, comunicando por meio de ações que pretendem experienciar o espaço por inteiro?

Segundo Fochi (2015, p. 104), a linguagem que os/as bebês “(...) utilizam aparece desde o gesto até os sons dos balbucios e sorrisos, ou seja, a linguagem dos bebês está na ação”. Logo, como não agir sendo um/a espectador/a bebê? O que se pretende com bebês espectadores/as que necessitam ser segurados/as em espetáculos contemplativos que pressupõem a contenção de seus corpos? Por outro lado, há companhias que permitem que as crianças entrem em cena, inclusive, sugerindo a quebra total da quarta parede ${ }^{20}$, para que possamos ter performances junto e com aos/às bebês, ao invés de Teatros ${ }^{21}$.

Ao assistir aos espetáculos analisados, foi observado que os/as bebês balbuciavam, davam pequenos gritos, mexiam o corpo, sorriam. Havia várias conversas e momentos de profundo silêncio. "Que que é isso?”, perguntava várias vezes uma bebê a cada coisa que as atrizes em $O$ que eu Sonhei?, da Cia. Zin, faziam. As crianças que já falavam, recriavam a dramaturgia da apresentação inteira, ou partes, repetindo as falas das atrizes (quando havia): " $A$

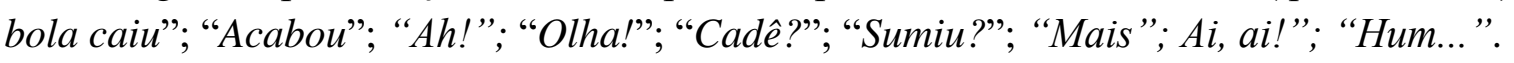

Ao longo das demais apresentações, as crianças repetiam, criavam, recriavam e ressignificavam os gestos e movimentações dos/as artistas, criando outros, semelhantes e complementares. Como apontou Corsaro (2011, p. 53), as “(...) crianças se apropriam criativamente das informações do mundo adulto para produzir sua própria cultura de pares". No processo de reprodução interpretativa, as crianças negociavam com adultos/as, com outras crianças e produziam criativamente por meio das culturas de pares. Elas transformavam as informações do mundo adulto, intuindo responder as suas preocupações.

Os/as artistas colaboradores/as da pesquisa trazem a convicção da capacidade dos/as bebês em dialogar esteticamente, por meio da sensibilidade e da poética que têm como humanos/as. Luiz André Cherubini, em debate no II Festival Primeiro Olhar, abordou uma das apresentações da Cia La Casa Incierta (LAREDO, 2003), em que a atriz após a apresentação, colocou uma gota de água na mão de cada bebê e eles/as entenderam que a gota de água tinha um significado diferente, que aquela água não era a água de todos os dias. Por isso, não a tomaram, nem limparam, apenas seguraram como algo muito importante e valioso. "E isso não é atribuir um significado poético? Então, o que seria?", questiona. Há uma comunicação que está sendo estabelecida, “(...) uma comunicação com pessoas [de pouca idade] que têm sensibilidade (...)" (CHERUBINI, 2013) que são capazes de compreender, a seu modo, a estética e a poética apresentada nas cenas ${ }^{22}$.

Ben Fletcher-Watson (2013) aborda uma criação pós-dramática para bebês, na qual as sequências coreografadas dos/as artistas foram intercaladas com momentos de improvisação livre e imitação ressignificadas, exigindo igualmente a presença de artistas e espectadores/as.

\footnotetext{
${ }^{20}$ Separação nítida entre plateia e palco (LEHMANN, 2007).

${ }^{21}$ Como na entrevista com a Cia. Zin, em 01/10/2011.

${ }^{22} \mathrm{Na}$ mesa redonda Criação no Teatro para Bebês - Pedagogia ou Poesia?, 23/08/2013, no Centro Livre de Artes Cênicas (CLAC), em São Bernardo do Campo/SP.
} 
Com isso, ao possibilitar a agência dos/as bebês para entrar e sair quando sentissem vontade, como espectadores/as emancipados/as que são, neste "Babydrama". Tratar-se-ia de oportunizar a experiência, a vivência e seus próprios escritos teatrais por meio da brincadeira livre no palco? Talvez a participação dos/as bebês no jogo teatral não devesse ser observada como uma interrupção da cena, mas como algo vital para a sua própria realização, em um processo que se retroalimentaria.

Ao ser concedida a entrada dos/as bebês nos espaços cênicos, oportunizar-se as experiências de meninos e meninas de pouca idade, possibilitando que estes/as criem suas próprias partituras corporais, experimentando a poética, o devanear-se, extraindo o 'e-movere', questionando estruturas pré-estabelecidas com base em um corpo “(...) estesiado, um corpo em movimento, um corpo linguageiro" (RICHTER, 2007, p.06). Traçar outras possibilidades de fazer Teatro em Performance é estar e ser em cena junto com pessoas de idades iguais e diferentes, possibilitando o convívio etário diversificado (PRADO, SILVA, 2016), transformando o espaço cênico em uma grande brincadeira ampliada (FLETCHER-WATSON, 2013).

Contudo, como campo em construção, não há certezas sobre o Teatro para bebês. O que se buscou neste artigo foi elencar o debate trazido em cena por artistas e espectadores/as de muita e pouca idade. A luta no agora é pela (re)existência e pelo acesso das crianças muito pequenas, como os/as bebês, aos espaços de Teatro e vice-versa. O caminho foi aberto e a temática já existe. Os/as bebês e seus/as acompanhantes, aos poucos, começam a ir ao Teatro para bebês, ainda que de forma tímida, restrita e privilegiada. Assim, a busca também se faz por políticas públicas que ampliem acessos de outros/as adultos/as e bebês, de diversas classes sociais, raças e etnias que, possivelmente, há muitas gerações foram extirpados/as dessa convivência poética.

\section{Considerações Finais}

Garantir o direito à cidade (HARVEY, 2013) e aos seus artefatos culturais (como os Teatros) supõe, dentre outras questões, a reapropriação desses tempos-espaços pelos sujeitos que a compõem, no sentido de pertencimento das cidades. Assim, investigar o Teatro para bebês é também abordar a possibilidade de que a cidade (e seus espaços de cultura) sejam de seus/suas habitantes, com base em sua participação, apropriação e transformação, visto que o direito à cidade está ligado ao direito de poder mudar a cidade de acordo com as necessidades e vontades daqueles/as que por ela circulam ou ocupam, refazendo-a.

Entendendo as dramaturgias para bebês como possíveis espaços que possibilitam outras experiências para além das cotidianas, de experimentação da estética, de vivência de múltiplas linguagens (EDWARDS; GANDINI; FORMAN, 1999), os espetáculos investigados vêm imprimindo marcas simbólicas e culturais, alterando a cadência e a estrutura cênica do Teatro, entendendo que as crianças, desde os/as bebês, não são apenas espectadores/as dos acontecimentos da vida, são sujeitos históricos e carregam em si o novo (LARROSA, 2003), nas transformações na concepção e estrutura do Teatro direcionado a eles/as, além de outras mudanças nos territórios que habitam.

Os/as bebês revelaram que não separam o conhecimento racional do corporal (PRADO, 1999; SAYÃO, 2008), vivenciando juntamente aos/às artistas as narrativas, os movimentos, as gestualidades e protagonismos de seus corpos, experimentando e vivenciando diversas e 
distintas linguagens como criadoras de seus faz de conta (MACHADO, 2010), devaneiam junto às cenas e avançam sobre os códigos teatrais, transgredindo o limite entre o palco e a plateia. Ao não necessitar parar de se mexer para compreender, as crianças trazem especificidades que são próprias desse momento da vida, dialogam com outras possíveis teatralidades, criam outras e são espectadores/as participantes e emancipados/as (FLETCHER-WATSON, 2013).

Os/as artistas dos Grupos Papo Corpóreo e Sobrevento e das Cias. Zin e Caixa do Elefante apresentam-se como investigadores/as constantes, na escuta e observação dos/as bebês antes, durante e depois dos espetáculos. Têm em comum os/as bebês como inspiração e contam que eles/as também "observam tudo, de olhos estalados", corpos que tremem, que querem ir para a cena, com onomatopeias, balbucios, que "sugerem coisas fundamentais". Na medida em que se expressam, ensinam sobre si e sobre um Teatro que se constrói na relação com o público e se retroalimenta na relação encenada em presença.

Talvez não seja só para o/a bebê, mas a partir de bebês você olha com olhar de quem, antropologicamente, em um determinado tempo histórico, está produzindo uma cultura diferente. (Entrevista com Cia. Zin, em 01/10/2011).

Os apontamentos e reflexões realizados ao longo deste artigo tiveram como objetivo traçar possíveis caminhos, na tentativa de responder algumas perguntas levantadas em relação ao Teatro para a primeiríssima infância, refletindo sobre o ganho social, estético, cultural ligado às possíveis experiências para e junto aos/às bebês, ainda que permeado de avanços e limitações adultocêntricas de compreensão das infâncias e de suas possibilidades.

Os materiais produzidos e analisados apontam, dentre outras questões, para uma problemática fundamental em relação à concepção, constituição e legitimação dos/as bebês como espectadores/as de Teatro - o que pode revelar novas concepções de infância, de educação e de Teatro, mais especificamente, em relação à primeiríssima infância, na construção de um Teatro que se torna para e com bebês, ao mesmo tempo e a partir das potencialidades corporais, poéticas, inventivas e interpretativas exibidas por eles/as.

Dessa forma, o Teatro para bebês liga-se, conecta-se a outra episteme, não mais apenas e exclusivamente europeia, decolonizando as pesquisas com crianças (ABRAMOWICZ; RODRIGUES, 2014), as concepções de infância, de educação e de artes na primeiríssima infância, no diálogo entre ancestral e contemporâneo, entre o sublime e o grotesco, não como uma imitação ou limitação da realidade.

\section{Referências}

AMARAL, Ana Maria. Teatro de formas animadas. São Paulo: Editora da USP, 1991.

ARTAUD, Antonin. O teatro e seu duplo. $3^{\text {a }}$ ed., São Paulo: Martins Fontes, 2006.

ABRAMOWICZ, Anete; RODRIGUES, Tatiane. Descolonizando as pesquisas com crianças e três obstáculos. Educ. Soc., CEDES, Campinas/SP, v. 35, n. 127, p. 461-474, 2014.

BARBOSA, Maria Carmen; FOCHI, Paulo. O teatro e os bebês: trajetórias possíveis para uma Pedagogia com crianças pequenas. Espaços da Escola. Ijuí/RS: Unijuí, , ano 21, n. 69, p.29-38, jan./jun. 2011.

BRASIL. Referenciais Curriculares Nacionais para a Educação Infantil. Brasília/DF: 
MEC/SEB, 1998.

CARNEIRO NETO, Dib. Pecinha é a vovozinha! São Paulo: DBA Artes Gráficas, 2003.

CARNEIRO NETO, Dib. Já somos grandes: Teatro Infantil, Entrevistas, Críticas, Debates, Balanços \& Rumos. São Paulo: Giostri, 2014.

CORSARO, William. Sociologia da Infância. Porto Alegre/RS: Artmed, 2011.

COSTAS, Ana Maria R. Processos de criação e pedagogia da dança: configurações de um ideário relacional. Relatório Pós Doutorado. ECA-USP, São Paulo, 2016.

ECO, Umberto. Obra aberta. São Paulo: Perspectiva, 1991. p. 07-73.

EDWARDS, Carolyn; GANDINI, Lella; FORMAN, George (Orgs.). As cem linguagens da criança: a abordagem de Reggio Emilia na educação da primeira infância. Porto Alegre/RS: Artes Médicas Sul Ltda., 1999.

FARIA, Ana Lúcia G.; RICHTER, Sandra Regina S. Apontamentos pedagógicos sobre o papel da arte na educação da pequena infância: como a pedagogia da Educação Infantil encontra-se com a arte? Small Size Paper. Bologna/IT: Pendragon, 2009, p.103-113.

FARIA, Ana Lúcia G.; DEMARTINI, Zeila B.; PRADO, Patrícia D. (Orgs.). Por uma cultura da infância: metodologias de pesquisa com crianças. $3^{\text {a }}$ ed., Campinas/SP: Autores Associados, 2009.

FERNANDES, Florestan. Folclore e mudança social na cidade de São Paulo. 2a ed., Petrópolis/RJ: Vozes, 1979.

FERNANDES, Sílvia. Grupos Teatrais- Anos 70. Campinas/SP: Editora da UNICAMP, 2000.

FLETCHER-WATSON, Ben. Child's Play: A Postdramatic Theater of Paidia for the Very Young. Staging Play, Playing Stages. Autumn, 2013, p.14-31.

FRABETTI, Roberto. Esiste um teatro per bambini? Small Size Papers. Theatre and Early Years: stories of artistic practices. Bologna/IT: Pendragon, 2009, p.65-80.

FOCHI, Paulo. Afinal, o que os bebês fazem no berçário?: comunicação, autonomia e saberfazer de bebês em um contexto de vida coletiva. Porto Alegre/RS: Penso, 2015.

GUÉNOUN, Denis. A exibição das palavras: uma ideia (política) do teatro. Rio de Janeiro: Teataro do Pequeno Gesto, 2003.

HARVEY, David. A liberdade da cidade. In: MARICATO, Ermínia et al. Cidades rebeldes: Passe Livre e as manifestações que tomaram as ruas do Brasil. São Paulo: Boitempo, Carta Maior, 2013, p.27-34.

HOLM, Anna Marie. Baby-art: os primeiros passos com a arte. São Paulo: MAM, 2007.

KOUDELA, Ingrid.; ALMEIDA JÚNIOR, José (Coords.). Léxico de pedagogia do teatro. São 
Paulo: Perspectiva, 2015.

LAREDO, Carlos. O olhar exilado das crianças. Boletín de la Institución Libre de Enseñanza. Madrid/ES, p. 49-50, jun. 2003.

LARROSA, Jorge. O enigma da infância: ou o que vai do possível ao verdadeiro. In: Pedagogia profana: danças, piruetas e mascaradas. Belo Horizonte/MG: Autêntica, 2003, p.183-198.

LEHMANN, Hans-Thies. Teatro pós-dramático. São Paulo: Cosac Naify, 2007.

LEHMANN, Hans-Thies. Teatro pós-dramático e teatro político. In: GUINSBURG, Jacó; FERNANDES, Sílvia. O Pós-dramático: um conceito operativo? São Paulo: Perspectiva, 2013, p.233-254.

LENGOS, Georgia (Org.). Põe o dedo aqui: reflexões sobre dança contemporânea para crianças. São Paulo: Terceira Margem, 2007.

LEYVA, Luvel. Em busca de uma semântica do teatro infantil. Revista Aspas. São Paulo: ECAUSP, v. 4, n. 2, p. 27-38, 2014.

LÜDKE, Menga; ANDRÉ, Marli E. D. Pesquisa em educação: abordagens qualitativas. São Paulo: EPU, 1986.

MACHADO, Marina. A Criança é Performer. Educação e Realidade. FE-UFRGS, Porto Alegre/RS, v. 35, n. 02, maio/ago. 2010, p.115-137.

MACHADO, Marina. Teatralidades na Tenra Infância, ou Bolacha recheada na cena contemporânea. Revista de Ensino de Teatro. UFMG, Belo Horizonte/MG, v. 01, n. 02, p.55-64, 2011.

MARTINS FILHO, Altino; PRADO, Patrícia D. (Orgs.). Das pesquisas com crianças à complexidade da infância. Campinas/SP: Autores Associados, 2011.

PAVIS, Patrice. Dicionário de teatro. São Paulo: Perspectiva, 2011.

PEREIRA, Luiz. Teatro para Bebês, estreia de olhares. Dissertação de Mestrado, UFF/RJ, Rio de Janeiro, 2014.

PRADO, Patrícia D. As crianças pequenininhas produzem cultura? Considerações sobre educação e cultura infantil em creche. Pro-Posições. FE-UNICAMP, Campinas/SP, v.10, n.1(28), p.110-118, 1999.

PRADO, Patrícia D. Por uma Pedagogia da Educação Infantil de corpos inteiros. In: MELO, José Carlos; CHAHINI, Telma H. (Orgs.). Reflexões \& Práticas na Formação Continuada de Professores da Educação Infantil. São Luís/MA, EDUFMA, 2015, p. 205-219.

PRADO, Patrícia D. “Como hacen eso?”: entrevistando artistas, refletindo sobre Dança e Teatro na Educação da primeira infância. In: ALMEIDA, Rogério; BECCARI, Marcos (Orgs.). Fluxos Culturais. Galatea, FEUSP, 2017, p.371-392. 
PRADO, Patrícia D., GOETTEMS, Milene B. Educação Infantil: tempos e espaços para danças e infâncias. Revista Chilena de Pedagogía, n.1, v.1, p.36-53, 2019.

PRADO, Patrícia D.; SILVA, Adriele N. Educación y edades de la primera infancia: relaciones con el Teatro para/con bebés. IV Foro Internacional de Investigadores y Críticos de Teatro para Niños y Jóvenes. Buenos Aires/AR, 2016.

PRADO, Patrícia D.; SOUZA, Cibele W. (Orgs.). Educação Infantil, diversidade e arte. São Paulo: Laços, 2017.

PROUT, Alan. The future of childhood: Towards the interdisciplinary study of children. New York/EUA: Routlege Falmer, 2005.

PUPO, Maria Lúcia. No reino da desigualdade: teatro infantil em São Paulo nos anos setenta. São Paulo: Perspectiva, 1991.

PUPO, Maria Lúcia. Fronteiras etárias no teatro: da demarcação à abertura. Revista USP. São Paulo, n. 44, p. 335-340, dez./fev. 1999/2000.

PUPO, Maria Lúcia (Org.). Tatiana Belinky: Uma janela para o mundo. Teatro para crianças e para todos. São Paulo: Perspectiva, 2012.

QVORTRUP, Jens. Visibilidade das crianças e da infância. Linhas Críticas. Brasília/DF, v. 20, n. 41, p. 23-42, jan./abr. 2014.

RICHTER, Sandra. Experiência poética e linguagem plástica na infância. Santa Cruz do Sul/RS, UNISC, GE: Educação e Arte, n. 01, 2007, p.01-06.

SARMENTO, Manuel. As culturas da infância nas encruzilhadas da Segunda Modernidade. Braga/PT: Instituto de Estudos da Criança, Universidade do Minho, 2003.

SARRAZAC, Jean-Pierre. A invenção da teatralidade. Sala Preta. ECA-USP, São Paulo, v.13, n.01, p.56-70, 2013.

SAYÃO, Deborah. Cabeças e corpos, adultos e crianças: cadê o movimento e quem separou tudo isso? Revista Eletrônica de Educação. São Carlos: UFSCar, v.2, p.92-105, nov. 2008.

SILVA, Adriele. Teatro para bebês: desafios em cena para as Artes e a Educação na primeiríssima infância. Dissertação de Mestrado, FEUSP, São Paulo, 2017.

SILVA, Adriele. Teatro para bebês na interface com a Educação Infantil: um diálogo possível? Trabalho de Iniciação Científica, FEUSP, São Paulo, 2012.

SILVA, Andrea F.; PRADO, Patrícia D. Que danças criam as crianças? Arte e corporalidade na educação das infâncias. In: SOUSA, Isabelle C. (Org.). Educação Infantil: comprometimento com a formação global da criança. Ponta Grossa/PR: Atena, p. 96-105, 2020.

SOUZA, Cibele W. Educação Infantil e Teatro: um estudo sobre as Linguagens Cênicas em propostas formativas, educativas e infantis da Rede Municipal de São Paulo/SP. Dissertação de Mestrado, FEUSP, São Paulo, 2016. 
SOUZA, Cibele W. As linguagens teatrais produzidas para e pelas crianças da Educação Infantil. Série Iniciação Científica FEUSP. FEUSP, São Paulo, v. 6, 2010.

VIEIRA, Miguel Velhinho. Ilo Krugli e a construção de um novo espaço poético para o teatro infantil. Dissertação de Mestrado. Rio de Janeiro: UNIRIO, 2008.

\section{Vídeos disponíveis em meios eletrônicos:}

SANTOS, Boaventura Souza. Classe em vídeo: Porquê as Epistemologias do Sul? S/D. Disponível em: https://www.youtube.com/watch?v=ErVGiIUQHjM. Acesso em: 01/04/2021.

\section{Entrevistas disponíveis em meios eletrônicos:}

Entrevista feita por Antonio Carlos Bernardes, em 15 de outubro de 2013, na sede do Grupo Sobrevento, em São Paulo, para o projeto Novo Sitio Web CBTIJ - Atualização da Memória, que recebeu o Prêmio FATE 2012, de la Secretaría de Cultura del Município do Rio de Janeiro. Parte de la entrevista con Luiz André Cherubini. Disponível em: http://cbtij.org.br/eduardotolentino-2/. Acesso em: 19 abr. 2021.

Entrevista com Elenira Peixoto, S/D. Disponível em: http://projetooqueeusonhei.blogspot.com.br/. Acesso em: 18 abr. 2021. 